\title{
Polis University as Lean Startup Innovation
}

\author{
Peter Nientied ${ }^{1}$ \\ ${ }^{1}$ NCOI University, Hilversum, the Netherlands and Polis University, Tirana, Albania \\ Correspondence: Peter Nientied, NCOI University, Hilversum, the Netherlands. Tel: 31-6-1445-8559. E-mail: \\ nientied1@chello.nl
}

Received: February 12, 2015

Accepted: March 5, 2015

Online Published: April 25, 2015

doi:10.5539/ibr.v8n5p19

URL: http://dx.doi.org/10.5539/ibr.v8n5p19

\begin{abstract}
This article studies the rapid development of a new university in Tirana, Albania, from the perspective of lean startup innovation. This is an unusual perspective because the lean startup approach is widely used for new ventures in the technology sector. The claim of principal authors of Lean Startup however is that the lean startup principles have much wider applicability than the tech sector. Based on the case study of a newly established university, it is concluded that this claim holds: the lean startup approach proves to be meaningful and relevant for understanding the rapid development of this university, and likely for other types of new business development as well.
\end{abstract}

Keywords: lean startup, innovation, business development, university, Albania

\section{Introduction}

The lean startup concept was introduced by entrepreneur Eric Ries. In 2011 his book 'The lean startup, How today's entrepreneurs use continuous innovation to create radically successful businesses was published, and attracted much attention, from both business and academic circles. It was a starting point for a kind of entrepreneurial and social movement (Note 1). The lean startup approach to innovation and entrepreneurship is meant to be used for developing innovative products and services in a close relationship with customers and can be seen as a synthesis of rapid and agile development and communication with the market. The core of the approach is minimising the time needed for the so-called feedback loop of building, measuring and learning. As Trimi and Bergebal-Mirabent $(2012$, p. 449) state “... the rationale behind the lean start-up approach is to optimize the utilization of scarce resources by using smaller and faster iterations for testing a vision continuously so as to get a desired product to customers' hands faster. To accomplish this goal, lean start-ups strive to minimize the expenditure of resources for anything but the creation of value for the customer."

The lean startup approach is sometimes said to be a practical methodology rather than an academic subject. This issue is discussed by Patz (2013). His point is that the lean startup concept does have an academic contribution (2013, p. 61): "The main theoretical contribution of the Lean Startup methodology to existing theories of entrepreneurial action like Effectuation and Bricolage, is adding the element of running experiments and stressing the learning aspect of the entrepreneur during the journey of starting a company." Ries (2011) combines startup disciplines and the Toyota Production system (lean manufacturing) and combined these two paths in the approach of lean startup (Blank, 2013). In other words, lean startup is progress in an intellectual and practice development. The lean startup methodology is taught at many universities. (Note 2) Academic interest is also shown through the research of Eisenmann et al. (2011) of Harvard Business School and publications of Blank (2013a; 2013b; 2005) and Blank and Dorf (2012). On technology and business blogs the topic of lean startup is widely discussed (Note 3 ).

The research question of this article is whether or not the lean startup concept is also relevant for a new venture that is very different from the typical Silicon Valley technology new businesses. In business contexts with high levels of uncertainty, entrepreneurs are forced to manage risks and to this end they use short cycles of experimentation (feedback loops) in the market. The lean startup approach demonstrates this mechanism through studies of technology startup ventures. Ries (2011), Blank (2013a) and Rancic Moogk (2012) claim that the lean startup approach has much wider applicability than just for new tech ventures. In other words, the proponents of lean startup approach put forward that this approach is applicable to many types of ventures. However, they do not provide evidence for this statement. Studying this claim is a new addition to understanding the relevance and 
applicability of lean startup principles.

Our case study is Polis University, a private sector university in Tirana, Albania, that was started in 2006 and has developed rapidly since. A new university in Albania is very different from a typical Silicon Valley lean startup, as one can imagine. A study of an Albanian new university can throw light on whether or not the claim of the wider applicability of the lean startup principles holds.

The remainder of this article is organized as follows. First a note is made on the research carried out. In section 2 key points of the lean startup approach will be summarized. Since the book of Ries and internet sources are widely available, this summary is concise. Then attention turns to the case of Polis University and the development on this new educational institution is sketched. In the analysis of the case, four theoretical pointers are applied:

- The main differences between a Silicon Valley tech startup and Polis University (context, nature of the enterprise, time frame minimum viable product)

- $\quad$ The model of Blank 'What start-ups do differently' (Blank, 2013a, p. 7)

- A model showing the difference between sustaining innovation and disruptive innovation (Cooper \& Vlaskovits, 2013, p. 54)

- $\quad$ The build-measure-learn feedback loop (Ries, 2011, p. 75).

In a concluding section, the relevance of the lean startup model for Polis University (and for wider application) is discussed, and an observation about uncertainty in new ventures' environments is submitted.

\subsection{Research Methodology}

Qualitative research (desk research, semi-structured interviews, analysis and reflection) was the basis for this study. The researcher has been involved in Polis University since its inception in 2006, as a visiting research fellow and lecturer. Each year, working visits have been made to contribute to various activities such as teaching subjects like 'the Creative City' and various management subjects to post graduate students, advising on research and conducting research, on the creative city and on innovation (Nientied \& Toto, 2009; Nientied \& Karafili, forthcoming).

The researcher carried out many interviews with Polis' Founding Board members, students, visitors, academic and support staff during the last years and has a good understanding of the development of Polis University, and the sometimes difficult Albanian working environment. In November 2014, semi-structured interviews on the startup and development of Polis were conducted with each of the founding members and with selected academic staff. Questions for the founding members (the entrepreneurs) included items regarding decision making, perception of risks, handling uncertainties, perceptions of the business environment, business challenged faced, learning, market feedback, and so on. The semi-structured interviews with selected academic covered topics like innovation, market information, quality issues and improvement of products and services, and so on. Additionally, information was gathered about basic facts like student enrolment, when exactly new events were started, and so on. This information is presented below. The answers to these questions resulted in a 'reconstruction' of the development of Polis University from the viewpoint of lean startup principles. During these interviews, the terminology of lean startup (unknown in Albania), was not used. By using models from the lean startup literature as a framework for the analysis, the researcher aimed to minimise subjective interpretation.

\section{Lean Startup}

Lean startup is a system for developing a business or product in the most efficient way possible to reduce the risk of failure. It is an approach for launching businesses and products that treats all product and business ideas as assumptions (or hypotheses) that must be validated by rapid experimentation in the marketplace. Lean is seen as 'avoiding waste' rather than reducing costs. Waste is for example developing something customers don't want. The lean startup approach relies on structured experimentation, iterative product releases, and customers' feedback to generate validated learning. Similar to the precepts of lean management, the lean startup approach seeks to eliminate wasteful practices and increase value producing practices during the product development phase so that startups can have better chances of success without requiring large amounts of outside funding, elaborate business plans, or the perfect product (Note 4).

The lean startup concept has been associated with the technology industry - how it approaches developing new products and how it looks at businesses. Ries (2011) uses examples from this sector and so do others authors (Cooper \& Vlaskovits, 2013; Rancic Moogk, 2012; Blank, 2013a; Munch et al., 2014; Humble et al., 2014). However, Ries states (2011) that his lean startup approach is not confined to any sector. Also Blank (2013a, pp. 
8-9) asserts that lean startup practices are not just for young tech ventures. He describes a case of General Electric Energy Storage division, which has been using the lean startup approach to transform the way it innovates. But the number of cases outside the technology sector is very limited, and the discussions on blogs are dominated by technology entrepreneurial topics.

Ries intentionally uses a broad definition for a startup: "A startup is a human institution designed to create a new product or service under conditions of extreme uncertainty" (2011, p. 27). Institution building means, according to Ries, that management is involved; building a startup is an exercise in institution building, and therefore it necessarily involves management. In fact, "Entrepreneurship is a kind of management" says Ries (2013, p. 3). Something new (or: innovation) is used by Ries (ibid.) in a broad sense - it is about a new source of value for customers and cares about the impact of its product on those customers. And Ries stresses the context, the conditions of high uncertainty. A measure for uncertainty is whether a loan officer in a bank understands the business and the model - he understands a proven model that can be cloned and depends on good execution limited risks. Lean startups create something new, with high uncertainty regarding business model, pricing, target customer and product. A loan officer would have troubles understanding is, and not be willing to provide a business loan.

Ries uses five principles that inform the approach of the lean startup (2011, p. 8):

1) Entrepreneurs are everywhere - not just in a garage, but in any size company.

2) Entrepreneurship is management - a startup is an institution, not just a product.

3) Validated learning - a startup learns how to build a sustainable business; it is not there to just make stuff or money.

4) Build-measure-learn - a startup is to turn ideas into products, measure how customers respond and then learn whether to pivot or persevere (i.e. a feedback loop).

5) Innovation accounting - a new way of accounting is needed to measure progress, set up milestones and how to prioritize work.

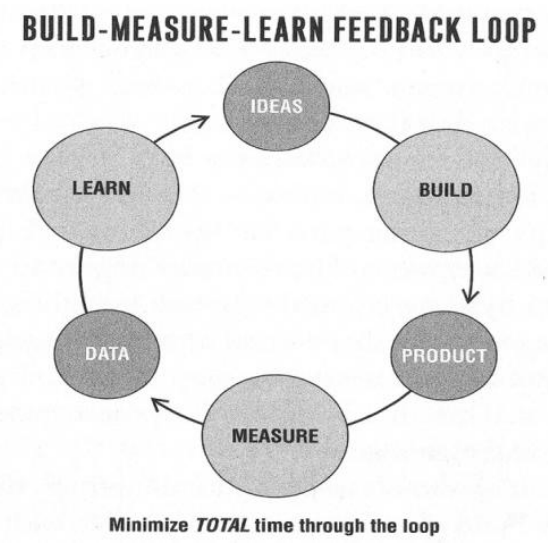

Figure 1. Feedback loop (Ries, 2011, p. 75)

The fourth principle warrants some further explanation. "At its heart, a startup is a catalyst that transforms ideas into products. As customers interact with those products, they generate feedback and data. The feedback is both qualitative (such as what they don't like) and quantitative (such as how many people use it and find it valuable)." (Ries, 2011, 75). The products of a startup are experiments, and the learning how to build a sustainable business is the outcome of those experiments. The point is minimizing the total time through this feedback loop. In the Build phase, a minimum viable product (MVP) is the result. On that result, feedback is generated through precise measuring. And from these data, lessons are learned, the idea is modified and the minimum viable product is adjusted - or skipped and a better product is built. The necessity to minimize the total time of the

feedback loop signifies the lean principles in uncertain environments: avoid wasting time and money to build a product that may not work in the market, build the case step by step.

\section{Polis University}

Is the lean startup approach indeed relevant for all organizations and not just for new tech ventures? An answer 
to this claim is given by means of a case study of Polis University (Note 5). This university was founded in 2006 and is located in Tirana, Albania. Albania is a small, post-communist middle income country with a GDP per capita of almost $\$ 4000$ and 3.2 million people (and a few million Albanian speakers in the neighbouring countries like Kosovo, Greece and Macedonia). In Albania, innovation is being talked about these days in government circles, but only very few innovative companies and organizations can be found. The reasons for that, and the perspective of companies that do innovate, are discussed elsewhere (Nientied \& Karafili, forthcoming).

Polis University was founded by four visionary and entrepreneurial professionals. Their main concern was not to create a product or make a lot of money, but to develop - in Ries' words - a human institution, aimed at delivering high quality higher education and research. The ambitions were high: have an impact on the way architecture and planning are practiced, set new standards in university education and even impact the moral, social and economic values of Albania. To sketch the context, it is important to mention the conventional approach to education in Albania. Students expect simple knowledge transfer from teachers who know what is best; many students are unmotivated and will get their diploma anyway. Corruption in schools is unfortunately not an exception. This depicts, unfortunately, much of the educational culture in Albania. Polis' founders had different ideas. Their aim was to create a high education institute based on modern values.

In economic terms, the 2006 period was rather favourable; the economy was growing rapidly (it slowed down in 2008). Parents who wanted the best for their children and could afford the fee, came to Polis University and accepted the modern didactical approach. With fellowships, Polis could attract some bright students who had limited resources. In the field of architecture and planning, the competitors were the state universities that provided their education for (almost) free, but the quality of their educational programs was questionable.

In the next chronological overview, the development of Polis University is depicted and tin Table 2, the student enrolment is shown.

Table 1. Main advancements of Polis university

\begin{tabular}{ll}
\hline 2006 & Establishment of Polis university, start of the Architecture program \\
2007 & Start of the Urban Planning and Management program \\
& Start of MetroPolis, design office \\
2009 & Institutional accreditation, establishment of formal structure incl. R\&D Centres \\
2010 & Transfer to a new building, \\
& Start of Applied Art Design Program \\
& Start of International Post graduate Master's program \\
2011 & Start of Environmental Studies program \\
2012 & Start of joint PhD program with University of Ferrara (Italy) \\
2013 & Start of a civil engineering school \\
\hline
\end{tabular}

Table 2. Number of students enrolled

\begin{tabular}{|c|c|c|c|c|c|c|c|c|c|}
\hline & Architecture & Planning & $\begin{array}{l}\text { Applied arts } \\
\text { (Bsc+MSC) }\end{array}$ & $\begin{array}{c}\text { Environ. studies } \\
\text { (Bsc + MSc) }\end{array}$ & MBA & Engineering & $\begin{array}{l}\text { EE (Energy } \\
\text { efficiency) }\end{array}$ & $\begin{array}{c}\text { Prof. Master } \\
\text { part-time }\end{array}$ & $\mathrm{PhD}$ \\
\hline $2006-7$ & 38 & & & & & & & & \\
\hline $2007-8$ & 64 & 15 & & & & & & & \\
\hline $2008-9$ & 49 & 12 & & & & & & & \\
\hline 2009-10 & 49 & 16 & & & & & & & \\
\hline 2010-11 & 34 & 12 & 13 & & & & & & \\
\hline 2011-12 & 52 & 16 & $21+6$ & $14+7$ & & & & 82 & \\
\hline 2012-13 & 37 & 34 & $23+5$ & $20+21$ & & & & 46 & 9 \\
\hline 2013-14 & 33 & 30 & $29+7$ & $15+14$ & & 16 & 14 & 32 & 12 \\
\hline 2014-15 & 23 & 16 & $32+5$ & $25+14$ & 17 & 16 & 25 & 27 & 13 \\
\hline
\end{tabular}


The number of full time staff by the end of 2014 was about 70 academic plus 25 administrative. Additionally, Polis University involves a substantial number of free-lance teaching staff. Polis obtained the required licenses for its educational programs, including in 2011 a license for starting a PhD program. Polis has a large number of international collaborations in European Union and Balkan countries and United States.

Polis does not consider itself to be a university whose sole purpose is to deliver higher education. The institution can be seen as a platform for various activities. Next to its academic education programs, Polis has developed a range of related activities.

- Polis started to publish the $A+P$ Journal in 2008, the only academic journal in the field of architecture and planning. Every issue, Polis manages to find sponsor funding.

- A Multimedia Art Design Centre \& Gallery was set up.

- An 'innovation factory' focusing on architecture, design and planning paradigms was started.

- Tirana Architecture Week (the architecture biennale) was initiated and also the Tirana Design Week (the design biennale) was launched.

- Polis participates in national debates, recently for example in the National Planning Strategy and the Albania Regionalisation Policy.

- Project offices of Metro-Polis (leading to architecture and planning projects) and Co-Plan Institute for Habitat development (projects in urban and regional management, environment and governance) are on the Polis campus.

- Polis implements demonstration projects, such as the redevelopment of a neighbourhood in Tirana, and it makes development plans for Albanian municipalities

- Polis carries out various training program for professionals in Albania, Kosovo, Macedonia, Montenegro and Bosnia.

At the start of Polis, in 2006, the business model of Polis was rather simple, close to $100 \%$ of Polis income came from student fees. In 2014 the business model is diversified: the share of income from students' fees was about $50 \%$ and income from various projects counted for the other $50 \%$.

In 2006 the main uncertainties were clear. First was the question of enrolment of students. The founders were very optimistic about that - and they proved to be right. Second, a major uncertainty was finding and attracting qualified academic staff, who shared Polis' values concerning educational quality and didactic approach. This concern proved to be correct. Especially during the first years Polis had to contract much staff from abroad. Polis did have the ambition to be an international university, but not to hire much part-time staff because of the extra costs involved. In 2006 the idea was to create a university in the field of architecture and planning-the development of other disciplines was not planned at that time.

In the current period 2014/2015, the main uncertainties have changed and the following are prominent. First is the uncertainty regarding the government policy of educational reform. It is clear that the present government seeks more control to ensure quality of education, but it is a question how this will be implemented and especially how far this control will go. Another uncertainty is that there are signals of a new 'brain drain'; the creative and high educated class loses its hope in Albania's future and goes abroad. An implication for Polis is that finding good academic staff will be more difficult.

\section{Results and Discussion}

As mentioned, Ries (2011) and Blank (2013a) do not limit the lean startup approach to tech ventures. On the contrary, they suggest that the lean startup approach has a much wider application. This is what is being studied. In the analysis of Polis University below, first a comparison is made of the business contexts of a lean startup reference venture (the archetypical tech startup in Silicon Valley is used as a reference) and Polis University in Albania. Then a model of Blank (2013a, p. 7) with an explanation of what start-ups do differently, is applied to the case of Polis, and the same is done with a model showing the difference between sustaining innovation and disruptive innovation (Cooper \& Vlaskovits, 2013). As a fourth model, the build-measure-learn feedback loop of Ries (2011, p. 75) is applied to Polis. Together, this should throw light on the claim whether the lean startup is relevant for Polis University, and if so, to many more different startups (or startup innovation activities in existing companies).

\subsection{Different Contexts}

Three main differences between a typical Silicon Valley technology startup and Polis University as a new 
entrepreneurial private sector university in a Balkan post-communist country are summarized in Table 3.

Table 3. Main differences contexts

\begin{tabular}{ccc}
\hline & Lean startup Silicon Valley & Polis University Tirana \\
\hline Nature of the enterprise & Technology, IT & $\begin{array}{c}\text { University, Architecture, Planning, } \\
\text { Design, Environment }\end{array}$ \\
\hline Environment & $\begin{array}{c}\text { Silicon Valley - innovation, network, } \\
\text { highly educated workers and entrepreneurs }\end{array}$ & $\begin{array}{c}\text { Albania - post-communist economy, } \\
\text { institution building, catching up }\end{array}$ \\
\hline Time frame for a minimal viable product & Weeks / months & Academic year (and longer) \\
\hline
\end{tabular}

\subsubsection{Nature of the Enterprise}

The lean startup approach is popular in the tech sectors. A university like Polis is quite different. The disciplines are different, the primary process is different, the stakeholders are different and the external environment is different. However, there are also similarities. Both have developmental and learning cultures and entrepreneurial attitudes.

\subsubsection{Environment}

The Albanian environment is very different from Silicon Valley: a post-communist small middle income country in Balkan Europe, versus a wealthy innovative region in the US. Economic, social and cultural realities are quite distinct. Yet, there is an interesting similarity in the business environments in Silicon Valley and Tirana: both business environments are dynamic, complex and very uncertain. The sources for uncertainty differ: in Silicon Valley the critical issues are the market and investor's finance, and in Albania it is the market, the government and other public bodies. Investor finance is not uncertain in the Albanian case-in 2006 it was just absent and that was known.

\subsubsection{Time Frame}

The time frames for developing a (minimal viable) product differ. Unlike the tech sectors, a university cannot do tests in weeks with a minimal viable product. The shortest possible cycle is a year-after finishing the process of obtaining the required government licenses. In the internet tech sector, minimum viable products can be a matter of weeks / months because market response can be organized in a fast manner.

\subsection{Polis as an Innovation}

Cooper and Vlaskovits (2013, p. 54) illustrate the differences between sustaining innovation and disruptive innovation (Table 4).

Table 4. Sustaining and disruptive innovation

\begin{tabular}{ll}
\hline Sustaining innovation & Disruptive innovation \\
\hline Problem is well understood & Problem not well understood \\
Existing market & New market \\
Innovation improves performance, lower cost, incremental change & Innovation is dramatic and game changing \\
Customer is believable & Customer doesn't know \\
Traditional business methods are sufficient & Traditional business methods fail. \\
\hline
\end{tabular}

Disruptive innovation requires a lean startup approach. The five criteria will be discussed for the case of Polis University, and it will be concluded that Polis University is a disruptive innovation in the Albanian context.

\subsubsection{Problem}

The problem of low quality higher education in Albania was well understood by the founders of Polis University, but the problem 'how to solve this', how to set up a sustainable institution that delivers high quality, was not understood at all. The problem was not only 'how to develop a high quality product', rather how to build a sustainable institution capable of delivering high quality education and having a relevant social impact. For Polis 
University, examples or reference cases in Albania or other Balkan countries were not available, and examples of new universities abroad did not match (longer time frames, more funding available). In 2008 there were private universities in Albania-many of them with the objective of making high profits. Only 4 out of 17 were accredited by the state. In 2014, a number of universities were closed by the state because of poor quality. The other universities are subject to an accreditation process - an uncertainty for Polis University: will the result be based on merits or on other, unknown grounds.

\subsubsection{Market}

In 2006 there was a situation with free public sector university education and private sector paid education of often questionable quality. Polis introduced a paid and specialized university education with high quality. The market response was unknown.

\subsubsection{Innovation}

Offering serious programs in the fields of architecture and planning education with a set of governing values and against a fee, was new. The business model of Polis University was not based on price leadership, on the contrary. Students had to pay a fee that was in the Albanian market on the high side. It was a question at the time of the startup, whether students would register. Investments were made in hiring a building, furbishing, getting teaching staff, organize a library etc. Polis University was not a credible institution on basis of its artefacts (students, professors, building, and library). The reputation of its founders was important.

Business angels, bank loans or other sources for initial finance were not available and the founders invested their own money. Because of financial limitations and the highly uncertain environment, Polis University developed a minimum viable product. It developed a curriculum for the first period only because it made no sense to develop more than what was needed in a short run, and it was too expensive too.

\subsubsection{Customers}

Polis offered something new on the market, and customers (students and their parents) and other stakeholders (institutions) did not know what to think of it. Parents wanted good education for their children and knew that public universities delivered low quality, but did not know what a new university would do. Institutions were sceptical, but that was seen as a recommendation. As one of the founders said: "the planning and architecture establishment was sceptical, and they were right because we were very critical of their role and functioning".

\subsubsection{Business Method}

Traditional business methods (working with a detailed business plan, find investors, make a high quality finished product and offer it to the market etc.) were for sure inadequate In the case of Polis. There were no investors, and no bank would step into this venture because of the uncertainties (not only the market, but also the political and institutional environment). Some verbal opposition from institutions were seen as a recommendation, but if leaders of those institutions conditions (like the National Planning Institute) would try to organize political forces, this would be harmful (like: not getting a government license). It meant a balanced and positive approach towards authorities and rapidly developing an own strong position in the force field.

\subsection{Polis as Lean Startup}

Blank (2013a, p. 7) gives an overview of what lean start-ups do differently. His main point is: the founders of lean startups don't begin with a business plan; they begin with the search for a business model. And only after quick rounds of experimentation and feedback reveal a model that works do lean founders focus on execution.

Table 5. Lean versus traditional startup

\begin{tabular}{lll}
\hline & Lean startup & Traditional startup \\
\hline Strategy & Business Model & Business Plan \\
& Hypothesis driven & Implementation driven \\
New product / process & Customer development & Product management \\
& Get out of the office and test hypotheses & Prepare offering for market following a linear, \\
& & step-by-step plan \\
Engineering & Agile development & Agile or waterfall development \\
& Build the product interatively and incrementally & Build the product iteratively, or fully \\
& & Specify the product before building it \\
\hline
\end{tabular}




\begin{tabular}{lll}
\hline Organization & Customer and agile development teams & Departments by function \\
& Hire for learning, nimbleness and speed & Hire for experience and ability to execute \\
Financial reporting & Metrics that matter & Accounting \\
& $\begin{array}{l}\text { Customer acquisition cost, lifetime customer } \\
\text { value, churn, viralness }\end{array}$ & Income statement, balance sheet, cash flow statement \\
Failure & $\begin{array}{l}\text { Expected } \\
\text { Fix by iterating on ideas and pivoting away from }\end{array}$ & Fix by firing executives \\
& ones that don't work & \\
Rpeed & Rapid & Measured \\
& Operates on good-enough data & Operates on complete data \\
\hline
\end{tabular}

\subsubsection{Strategy}

Polis' strategy was driven by its mission and by a hypothesis. The mission of Polis was right from the start: provide "space for thinking" about territorial development policies, architecture, technology and leadership and entrepreneurship. In August 2006 the hypothesis was: 'Polis University can get adequate enrolment of students paying a fee for quality education, in October we know whether we have achieved the number of students to break even'. An underlying assumption was that the market would see and appreciate the difference between quality higher education that Polis wanted to provide, and cheaper low quality education offered by other (public and private) higher education institutes. In fact, Polis wanted to attract motivated people, and provided a number of partial fellowships for aspiring students who could not afford the admission fee.

\subsubsection{New Product / Process}

Polis developed a completely new curriculum. The Polis founders had foreign university degrees and good reputation as professionals. The idea was to convince students during the first year that they had to work hard and then would achieve something. 'Getting out of the office' was important for Polis although the customers came to the office (the university)-getting out meant a lot of indirect marketing and public relations, meetings with government officials, interviews on television, etc. And for the education product: students get out of the university, conduct action research and see through other eyes what is going on in the reality of cities.

\subsubsection{Engineering}

The product was developed while running the educational programs. Polis worked with a minimum viable product. This product had its minimum specifications (the basis was: European quality standards, the so-called Bologna criteria, a government licence to operate, and attracting the best possible academic staff). Execution was part of the startup right from the start, because of the duration of the business cycle. That is one academic year, but in fact longer since customers are given the promise that they will receive high quality education for a number of years for their bachelor's and Master's studies.

\subsubsection{Organization}

A university as a startup implies a lot of management. The rules and regulations of the Albanian Ministry of Education are very detailed, and those of the tax office and other public institutions too. Formally, the university is organized in departments by function (as is required by the Ministry of Education). In practice Polis University works a lot with teams. From the start, Polis University put in much effort to find professionals with a right attitude - eager to learn and develop, hands-on mentality, able to manage professional and operational autonomy. Finding good staff was (and is) a challenge, especially attracting professionals with a $\mathrm{PhD}$ who adhere to Polis' values, is difficult. Because Polis University has an international focus, foreign staff was contracted. Polis University dismissed people who did not live up to the expectations. All 'permanent' staff works with a renewable temporary contract of one year.

\subsubsection{Financial Reporting}

Due to various regulations, Polis works with accounting, income statements, balance sheets, and so on, and good bookkeeping is required. But what mattered more, was value creation through higher education and other activities: students getting jobs or meeting requirements for further studies abroad, research contributions, appearances on television and influencing the public at large, recognition of submissions in process, qualifying for international collaborations. 


\subsubsection{Failure and Speed}

At the start, the hypothesis of the founding member was positive. The notion was: 'we have to give this a try; we owe it to ourselves and to the future of the country'. But failure was considered to be a real option, and the founders were well aware of the risks of their new institution.

\subsection{Build-Measure-Learn}

The build-measure-learn feedback loop is applied by Polis, albeit that a feedback loop for the primary process takes an academic year. Given the uncertain environment and the limited financial means, Polis is reluctant to spend funds on overheads. But as the institutions grew, this was unavoidable. After three successful years, Polis needed more space and moved to another building outside the city centre. A very innovative arrangement was developed with the owner of a textile company who had too much space (including an exchange of architectural services for space). But it implied an investment for IT, refurbishment and a new façade (Note 6).

In a lean startup testing a single hypothesis (say: how the market responds to a new app), the build-measure-learn feedback loop (see Figure 1) is easier to understand than an institution like a university where many different feedback loops have to be simultaneously applied. The main feedback loop at the start was the value created through offering architectural education. Now there are a number of educational programs running at the same time, plus research cycles, an innovation workplace and various supporting processes.

\section{Conclusions}

In 2006, well before Ries' (2011) book The lean startup was published and lean startup language was introduced, Polis University was started. It has been shown in this article that the development of Polis University can be well understood in terms of lean startup. By way of conclusion, the five principles of the lean startup approach are applied to the case of Polis university, and the question will be answered how lean startup was applied before the concept was even described by Ries in 2011.

1) Entrepreneurs are everywhere-not just in a garage, but in any size company. This fits: The founders did not start in a garage in Silicon Valley, but in an office in Tirana, Albania. The founders made their plans and rented a building that was equipped as a university. The entrepreneurial spirit of the start is part of the present culture.

2) Entrepreneurship is management-a startup is an institution, not just a product. This applies: Polis University is a human institution designed to create new products and services. It developed into a small modern university with now close to 100 staff and quite a bit of imposed bureaucracy. That requires management. Polis founders control the administrative processes well, while keeping a focus on what Polis is about - its mission and its academic activities. They have been able to do so under conditions of high uncertainty.

3) Validated learning-a startup learns how to build a sustainable business; it is not there to just make stuff or money. This also applies. Polis University is now in business since 2006, and in this period Polis has demonstrated that it is building up a sustainable business. Because of the high uncertainty in the environment and the limited financial means, new activities almost automatically follow a validated learning routine: try something as small as possible (a minimal viable product, small but big enough to give a good idea), learn, improve, etc.

4) Build-measure-learn-a startup is to turn ideas into products, measure how customers respond and then learn whether to pivot or persevere (i.e. a feedback loop). In the case of Polis University, the feedback loop based on customers' response, is different from a technology company developing a new web based service. The business cycle is longer; feedback comes from many different sources (not only students, but also their parents who pay, from government officials, professional circles, and so on). After Polis University started in 2006, much effort was put into reputation management-mostly through professional activities. For Polis University, the build-measure-learn feedback loop comes close to validated learning, the third component of the lean startup approach.

5) Innovation accounting-a new way of accounting is needed to measure progress, set up milestones and how to prioritize work. Polis started with a minimal viable product and initially innovation accounting was based on enrolment figures. Now the products and services offered by Polis are diverse and accounting is formalized. For new services, a minimal viable product is developed and the feedback loop informs the founders about the prospects.

Two questions remain to be answered. The first is: how come that Polis developed as a lean startup while the 
lean startup approach was not even developed? The answer lies in dealing with uncertainty, to be more precise: entrepreneurial behaviour in a highly uncertain business environment. High uncertainty is defined as '(almost) unknown unknown' in opposition to risk, which is 'known unknown' (Bonazzi \& Perruchoud, 2014; Thompson \& MacMillan, 2010). High uncertainty is something that innovative entrepreneurs in Silicon Valley and in Albania have in common. Conditions in Albania around 2006 (uncertain, complex, dynamic, no funds available for innovation) can be seen as a push factor for lean startup: don't risk (possibly waste) too much, go step by step in a rapid manner, learn from the experiences. Looking back and combining the three factors a) limited financial resources, b) high ambitions and c) a highly uncertain business environment, lean startup behaviour of Polis University can be seen as a common-sense entrepreneurial attitude. This links well to what McGrath (2010) calls a 'discovery driven approach'.

A second question is about the minimum viable product and the duration of the feedback loop. In the case of Polis University, a minimal viable product should be good enough not only for the market but also for the government. The time frame was not a matter of weeks/months, but rather a year and longer. In many other sectors like biotech, agriculture, engineering and pharmacy, minimum viable products and time frames / feedback loops also require longer periods of time. However, the principle of the shortest possible feedback loop is valid.

This case study showed that the lean startup approach is relevant and meaningful for understanding the development of a new university, a very different institution in a very different environment than the typical new tech venture. Most likely the lean startup approach is relevant for other businesses as well, both new businesses and development of innovations in existing organizations. Whether or not these are businesses, not for profit organizations or government organizations, is not very important. The objective to reduce risks, high uncertainty in the business environment and agile innovation management are. This is a promising area for further empirical research with practical and theoretical relevance. More empirical research will inform organizations on the possible application of lean startup principles in their business sector. And more empirical research in various sectors will also help to develop theory, for example whether the build-measure-learn feedback loop and innovation accounting could be elaborated for non-technology sectors with longer business cycles.

\section{Acknowledgements}

Thanks to Dr. Rob Reitsma for comments and to Prof. Besnik Aliaj, Sotir Dhamo, Elona Karafili and Dritan Shutina for their collaboration.

\section{References}

Blank, S. (2013a). Why the lean start-up changes everything. Harvard Business Review, May, 3-9.

Blank, S. (2013b). The four steps to the epiphany, successful strategies for products that win (2nd ed.). Pescadero CA: K\&S Ranch.

Blank, S., \& Dorf, B. (2012). The startup owner's manual. Pescadero CA: K\&S Ranch.

Bonazzi, R., \& Purrechoud, A. (2014). Combining the notions of "lean startup" and "effectuation" to teach future entrepreneurs. Interdisciplinary European Conference on Entrepreneurship Research IECER, February 12-14, 2014, Chur Switzerland.

Cooper, B., \& Vlaskovits, P. (2013). The lean entrepreneur. Hoboken, Wiley.

Eisenmann, T., Ries, E., \& Dillard, S. (2013). Hypothesis-driven entrepreneurship: The lean startup. Harvard Business School Background Note 812-095.

Gothelf, J. (2013). Lean UX, Applying lean principles to improve user experiences. Sebastopol CA, O'Reilly Media.

Humble, J., Molesky, J., \& O’Reilly, B. (2014). Lean enterprise: How high performance organizations innovate at scale. Sebastopol CA, O'Reilly Media.

McGrath, R. G. (2010). Business models: A discovery driven approach. Long Range Planning, 43(2), 247-261. http://dx.doi.org/10.1016/j.lrp.2009.07.005

Münch, J., Fagerholm, F., Johnson, P., Pirttiluhati, J., Torkkel, J., \& Järvinen, J. (2014). Creating a minimum viable product in industry-academia collaborations. Proceedings of the Lean Enterprise Software and Systems Conference, LESS 2013, Galway, Ireland, December 1-4.

Nientied, P., \& Karafili, E. (forthcoming, 2015). The innovation challenge in the Balkan. Tirana, Polis University. 
Nientied, P., \& Toto, R. (2009). The concept of the creative city in the Balkan region context. A+P Journal, (2), 110-121. http://www.universitetipolis.edu.al/?q=en/node/752

Patz, M. (2013). Lean Startup - adding an experimental learning perspective to the entrepreneurial process. MSc Thesis Business Administration, Universiteit Twente/Technische Universität Berlin. Retrieved from http://essay.utwente.n1/62938/1/final_MaThesis_Patz.pdf

Rancic, M. D. (2012). Minimum viable product and the importance of experimentation in technology startups. Technology Innovation Management Review, March, 23-26.

Ries, E. (2011). The lean startup. New York, NY: Crown Business.

Ries, E., \& Euchner, J. (2013). What large companies can learn from start-ups: An interview with Eric Ries. Research-Technology Management, July—August, 12-16.

Thompson, J. D., \& MacMillan, I. (2010). Business models: Creating new markets and societal wealth. Long Range Planning, 43(2), 291-307. http://dx.doi.org/10.1016/j.lrp.2009.11.002

Trimi, S., \& Berbegal-Mirabent, J. (2012) Business model innovation in entrepreneurship. International Enterprise Management Journal, 8, 449-465. http://dx.doi.org/10.1007/s11365-012-0234-3

\section{Notes}

Note 1. People in over 500 cities worldwide organize meetups on lean startups, and its web platform, the lean startup circle, has over 80.000 members. See: //leanstartupcircle.com/ (accessed 20 October 2014).

Note 2. See //www.steveblank.com for more information.

Note 3. Wikipedia gives a number of references to publications, talks, cases, etc. See http://en.wikipedia.org/wiki/Lean_startup (accessed 1 March 2015)

Note 4. http://leanstartup.pbworks.com/w/page/65946049/Intro\%20to\%20Lean\%20Startup (accessed 1 March 2015)

Note 5. See http://www.universitetipolis.edu.al/?q=en

Note 6. See the Polis website http://www.universitetipolis.edu.al/?q=en for pictures.

\section{Copyrights}

Copyright for this article is retained by the author(s), with first publication rights granted to the journal.

This is an open-access article distributed under the terms and conditions of the Creative Commons Attribution license (http://creativecommons.org/licenses/by/3.0/). 